\title{
PENYULUHAN SANITASI KOMUNAL DI DESA TAMBAK BARU KECAMATAN MARTAPURA KOTA KABUPATEN BANJAR
}

\author{
Eka Purnamasari, Akhmad Gazali, dan Robiatul Adawiyah \\ Fakultas Teknik, Universitas Islam Kalimantan MAB \\ E-mail : eka.ftsuniska@gmail.com
}

\begin{abstract}
Tambak Baru is one of 25 villages. Village located in the District Martapura Banjar district. The majority of the population are farmers Tambak Baru (peasant) and household handicraft industry and artisan labor. Geographically, the new Village Pond located at coordinates between $3.23594^{\circ} \mathrm{S}$ and $114^{\circ} 35^{\prime} 30$ "- $114.52134^{\circ}$ East.

Wastewater contained in Tambak Baru generally in the form of domestic waste / household. The waste water typically flows into the river nearby, so the burden of the rivers in the region is getting heavier and river water pollution level is high enough. It can be seen from the river in the region. And in the rainy season drainage is not functioning properly so frequent inundation at certain points.

Based on the characteristics of the Tambak Baru, District Martapura Banjar Regency, it can be concluded that the aspect of social affecting people in Tambak Baru, District Martapura Banjar district in the act defecating carelessly, among other factors economic, education and mindset of the people in the act defecating, To achieve the target stop Babs performed triggered activity, in order to achieve behavioral change in behavior by simulation calculations Babs feces and fecal water, because people dump sludge into the river. The technical aspects of the constraints is the topography factor (nearby river with settlements), and lack of availability of land as a result of the density of homes that use a centralized waste management system and WWTP Communal.
\end{abstract}

Keywords: New Pond Village, Banjar District, Sanitation, Environment, Communal

PENDAHULUAN

Desa Tambak Baru adalah salah satu dari $25 \mathrm{desa} /$ Desa yang terdapat di wilayah Kecamatan Martapura Kabupaten Banjar. Mayoritas dari penduduk Desa Tambak Baru adalah petani ( buruh tani ) dan industri kerajinan rumah tangga serta buruh tukang. Secara geografis Desa Tambak baru terletak pada koordinat antara $3,23594^{\circ}$ LS dan 114'35'30'$114,52134^{\circ} \mathrm{BT}$
Batas wilayah Desa Tambak Baru adalah :

> Sebelah Barat berbatasan dengan desa Bincau Muara

$>$ Sebelah Timur berbatasan Desa Tambak Baru Ilir

$>$ Sebelah Selatan berbatasan dengan Desa Bincau

$>$ Sebelah Utara berbatasan dengan Desa Tambak Anyar Ilir

Dengan topografi dataran rendah, sebagian besar wilayahnya adalah lahan 
persawahan dan lebak /rawa dangkal. Karena termasuk kawasan rendah inilah, maka permasalahan tahunan yang dialami desa ini adalah masalah banjir.

Desa Tambak Baru ini wilayahnya berada jauh dari pinggiran kota sehingga untuk menuju Ibukota Provinsi atau Pusat kegiatan ekonomi cukup sulit. Orang untuk menuju Pasar di Pusat perbelanjaan bisa menggunakan transport darat dan sungai. Jarak antara Desa dengan Ibukota Kabupaten $2 \mathrm{Km}$, dapat di tempuh dalam 15 menit.Jarak terdekat Desa Tambak Baru dengan kota Kecamatan Martapura adalah kira-kira $5 \mathrm{~km}$, dengan waktu tempuh 25 menit. Sedangkan jarak Desa Tambak Baru dengan Kota Kabupaten adalah $3 \mathrm{~km}$ dengan waktu tempuh 15 menit.

Air limbah yang terdapat di Desa Tambak Baru umumnya berupa limbah domestik/rumah tangga. Air limbah tersebut umumnya dialirkan kesungai terdekat, sehingga beban sungai-sungai di wilayah tersebut semakin berat dan tingkat pencemaran air sungai cukup tinggi. Hal ini dapat dilihat dari kondisi sungai yang ada di wilayah tersebut.Dan pada musim hujan drainase tidak berfungsi dengan baik sehingga sering terjadi genangan pada titiktitik tertentu.

Sistem pengolahan limbah dari septictank dan cubluk relativesedikitmengunakannya. Hal ini disebabkan oleh beberapa kecendrungan yaitu :
- Kurang sadarnya peduduk setempat akan arti kebersihan dan kelestarian lingkungn

- Biaya pembuatan system pengolahan yang relative memberatkan

- Faktor budaya masyarakat yang belum terbiasa dengan system pengolahan limbah tersebut.

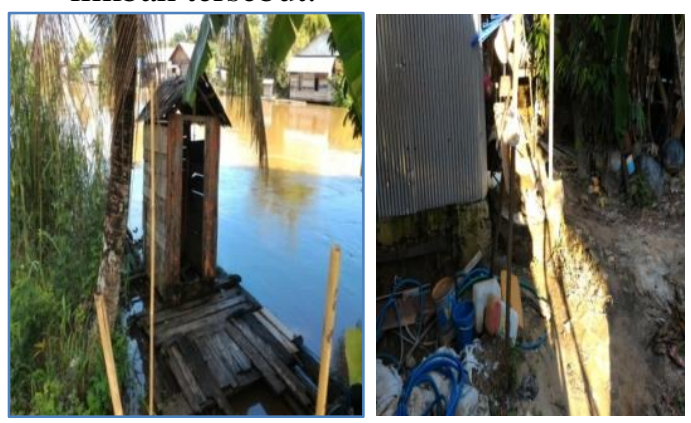

Gambar 1. Kondisi Desa Tambak Baru

Pengabdian pada masyarakat ini bertujuan untuk membantu masyarakat dalam:

a. Penyelenggaraan sosialisasi perlunya perilaku hidup bersih dan sehat.

Secara umum proses perubahan masyarakat yang diharapkan dari suatu kampanye publik adalah : Meningkatnya kesadaran (Awareness), meningkatnya minat (Interest), tumbuhnya kebutuhan (Demand) dan Adanya partisipasi dan tindakan (Action)

\section{KHALAYAK SASARAN}

Sasaran utama kegiatan ini adalah kepala desa, perangkat desa, tokoh masyarakat, pemuda dan ulama 
masyarakat desa Tambak Baru kecamatan martapura kota kabupaten banjar. Karena mereka dapat menyebarluaskan hasil kegiatan pada anggota sasaran yang lain.

\section{METODE}

Pelaksanaan program sosialisasi tentang sanitasi komunal dilakukan dengan metode ceramah dan Tanya jawab.

1. Tahap persiapan

Tahap persiapan dalam kegiatan pengabdian ini adalah penyusunan pre planning.Persiapan media berupa power point dengan materi penyuluhan mengenai sanitasi komunal.Langkah pertama adalah membuat kontrak, waktu dan tempat penyuluhan dengan kepala desa setempat.

2. Tahap pelaksanaan

Kegiatan penyuluhan ini dilakukan dengan cara mengumpulkan warga dengan koordinasi kepala desa. Materi akan diberikan kepada para peserta berupa buku dan gambargambar.Diakhir pemberian ceramah peserta dipersilahkan diberi kesempatan untuk melakukan Tanya jawab dengan narasumber. Diharapkan dari sini maka para peserta akan mengerti dan dapat memberikan masukan kepada orang tua dan keluarga mereka.

\section{HASIL DAN PEMBAHASAN}

Perilaku hidup bersih dan sehat (PHBS) adalah semua perilaku kesehatan yang dilakukan atas kesadaran semua anggota keluarga dan masyarakat, sehinggakeluarga dan masyarakat itu dapat menolong dirinya sendiri dan berperan aktif dalam kegiatan-kegiatan kesehatan di masyarakat.

Dalam lingkup rumah tangga, untuk ber-PHBS kegiatanya cukup banyak seprti tidak merokok dalam rumah, memberi ASI, menimbang balita secara rutin, memberantas jentik nyamuk, dll. Sebagaimana tercakup dalam Sanitasi Total Berbasis Masyarakat (STBM), ada 4 pilar verPHBS, yaitu:

- Stop Buang Air Besar Sembarangan (STOP BABS),

- Cuci Tangan Pakai Sabun (CTPS)

- Pengamanan Air Minum Rumah Tangga

- Pengelolaan Sampah Rumah Tangga

- Pengelolaan Air Limbah Rumah Tangga

Sampai saat ini, diperkirakan sekitar $47 \%$ masyarakat Indonesia 
masih buang air besar sembarangan, ada yang berperilaku buang air besar ke sungai, kebon,sawah, kolam dan tempat-tempat terbuka lainnya. Perilaku seperti tersebut jelas sangat merugikan kondisi kesehatan masyarakat, karena tinja dikenal sebagai media tempat hidupnya bakteri coli yang berpotensi menyebabkan terjadinya penyakit diare. Tahun 2016 sebesar 423 per 1000 penduduk terserang diare dengan angka kematian sebesar 2,52\%.

Berbagai alasan digunakan oleh masyarakat untuk buang air besar sembarangan, antara lain anggapan bahwa membangun jamban itu mahal, lebih enak BAB di sungai, tinja dapat untuk pakan ikan, dan lain-lain yang akhirnya dibungkus sebagai alasan karena kebiasaan sejak dulu, sejak anakanak, sejak nenek moyang, dan sampai saat ini tidak mengalami gangguan kesehatan.

Alasan dan kebiasaan tersebut harus diluruskan dan dirubah karena akibat kebiasaan yang tidak mendukung pola hidup bersih dan sehat jelas-jelas akan memperbesar masalah kesehatan. Dipihak lain bilamana masyarakat berperilaku higienis, dengan membuang air besar pada temapt yang benar, sesuai dengan kaidah kesehatan, hal tersebut akan dapat mencegah dan menurunkan kasus-kasus penyakit menular. Dalam kejadian diare misalnya, dengan meningkatkan akses masyarakat terhadap sanitasi dasar, dalam hal ini meningkatkan jamban keluarga, akan dapat menurunkan kejadian diare sebesar 32\%.

Karaktristik dan pola hidup masyarakat sangat dipengaruhi oleh tingkat pendidikan. Tingkat pendidikan yang rendah berpengaruh terhadap pengetahuan akan pentingnya kebersihan dan kesehatan lingkungan, khususnya dalam hal ini adalah pengetahuan tentang sanitasi. Pengetahuan masyarakat tentang sanitasi mempengaruhi pola pikir dalam hal sanitasi, hal ini berdasarkan hasil wawancara kepada tokoh masyarakat bahwa $75 \%$ dari tokoh masyarakat tidak mengetahui apa itu sanitasi lingkungan. Hal ini disebabkan karena masyarakat tidak pernah mendapatkan penyuluhan/pemicuan yang berkaitan dengan sanitasi. Selain itu, jika ada penyuluhan tentang sanitasi hanya sebatas sampai masing-masing ketua RT dan belum tersosialisasi kepada masyarakat. Akibat dari tidak adanya penyuluhan/pemicuan kepada masyarakat tentang boleh atau tidaknya 
buang air besar di sungai dan dampak yang ditimbulkan, sehingga masih banyak masyarakat yang melakukan praktek buang air besar di sungai.

Perilaku sanitasi masyarakat berdasarkan hasil wawancara kepada tokoh masyarakat didapatkan informasi bahwa masih banyak masyarakat yang tidak memiliki jamban, dengan alasan dekat dengan sungai dan tidak tersedianya jamban di rumah. Masyarakat masih menganggap jamban bukan sebagai kebutuhan, karena mereka beranggapan masih banyak kebutuhan lain yang harus dipenuhi. Hasil wawancara dengan tokoh masyarakat diperoleh data bahwa masyarakat yang tidak memiliki jamban mayoritas $\mathrm{BAB}$ di sungai sebesar $70 \%$, sedangkan masyarakat yang sudah memiliki jamban namun jamban mereka langsung cemplung ke sungai sebesar $21 \%$, ini berarti masih buang air besar sembarangan. Selanjutnya, sisanya BAB di MCK sebesar 4\% dan 5\% yang BAB di jamban tetangga.

Faktor ekonomi juga mempengaruhi kemauan dan kemampuan masyarakat dalam membangun jamban. Dari informasi yang disampaikan tokoh masyarakat bahwa faktor ekonomi merupakan salah satu penghambat akses masyarakat terhadap sanitasi yang layak di Desa Tambak Baru Kecamatan Martapura ini. Namun berdasarkan hasil wawancara ini juga diperoleh data bahwa 100\% masyarakat menginginkan memiliki jamban sendiri tetapi tidak mau membangun dengan biaya sendiri, berharap agar ada bantuan dari Pemerintah sebesar 60\%, bantuan pemilik kontrakan sebesar $28 \%$ dan hanya $12 \%$ masyarakat yang mau menabung untuk membangun jamban. Masyarakat masih menganggap jamban bukan sebagai kebutuhan, sehingga diperlukan pemicuan agar memiliki jamban menjadi prioritas kebutuhan masyarakat.

Analisa aspek teknis untuk mengetahui kendala apa saja yang menjadi persoalan dalam pencapaian target stop buang air besar sembarangan. Desa Tambak Baru Kecamatan Martapura, memiliki kondisi lingkungan yang menunjang masyarakatnya untuk berperilaku BABs. Hal ini dikarenakan adanya sungai yang melintas di antara pemukiman warga.Jarak rumah dengan sungai sangat dekat sehingga masyarakat membuang hasil aktifitas mereka melalui dari mandi, mencuci, 
sampai kakus (tinja) langsung ke sungai (jamban). Lokasi BABs yang digunakan masyarakat meliputi jamban cemplung di rumah (a), jamban apung di sungai (b), maupun MCK yang sudah tersedia.

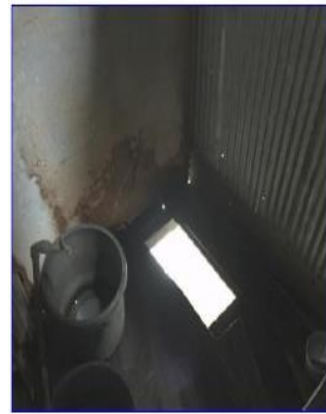

(a)

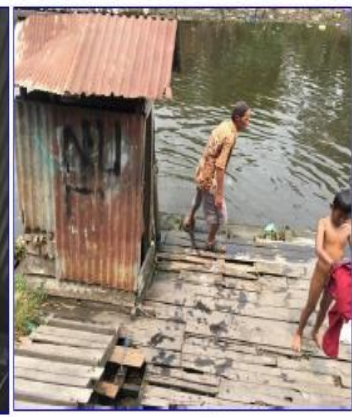

(b)
Gambar 2 . Kondisi Sanitasi Desa Tambak Baru

Informasi dari Tokoh Masyarakat "kendala teknis yang dihadapi adalah masalah lahan yang terbatas.Lahan yang terbatas disebabkan karena rapatnya rumah-rumah penduduk".Untuk mengatasi keterbatasan lahan sehingga digunakan halaman Sekolah Dasar Tambak Baru 1 sebagai tempat pembangunan IPAL.Berdasarkan informasi dari Dinas Cipta Karya dan Permukiman, kondisi tanah Desa Tambak Baru yang sebagian besar rawa merupakan kendala dalam pembuatan IPAL komunal.

Kondisi pasang surut sungai di Desa Tambak Baru, berdasarkan hasil observasi dan wawancara dengan warga yang tinggal di atas bantaran sungai, sungai Tambak Baru dipengaruhi oleh pasang surut air laut.Adanya pasang surut tidak menyebabkan terendam rumah warga, karena ketinggian rumah warga sudah disesuaikan dengan air pasang tertinggi.Untuk elevasi perpipaan rumah warga di atas bantaran sungai disesuaikan dengan air pasang tertinggi, agar menghindari pipa terendam air saat pasang.

\section{FOTO KEGIATAN}
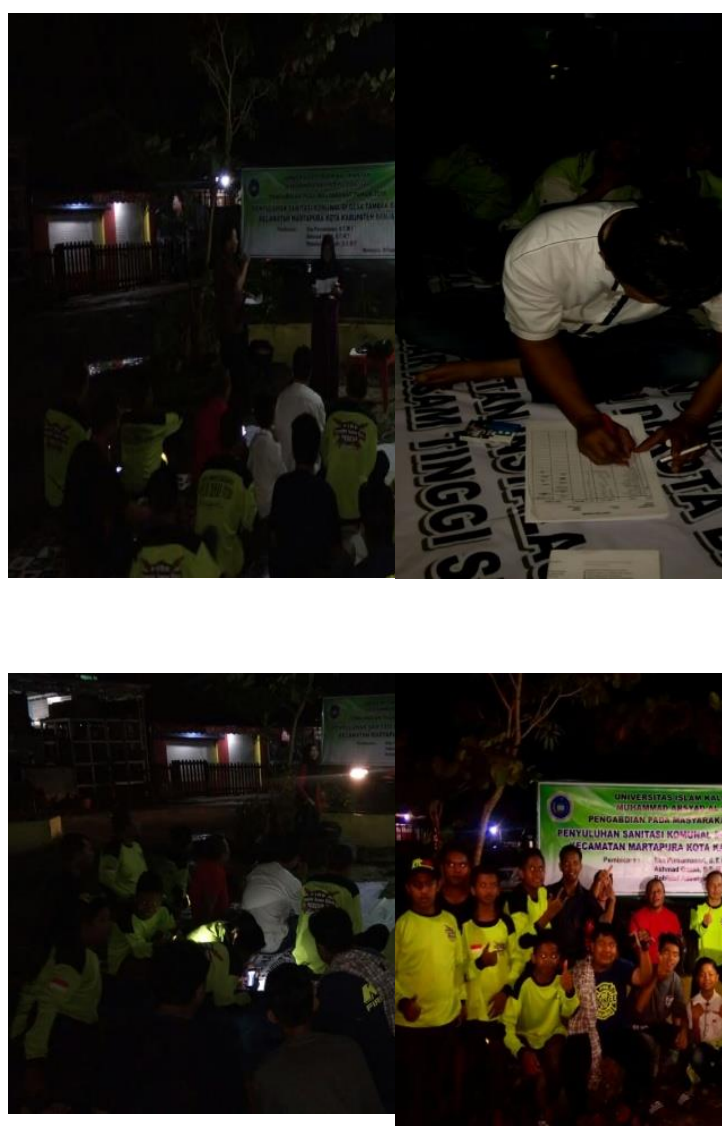

Gambar 3. Kegiatan Penyuluhan

\section{KESIMPULAN}

Berdasarkan karakteristik masyarakat Desa Tambak Baru, 
Kecamatan Martapura Kabupaten

Banjar, didapatkan beberapa

kesimpulan dalam pencapaian stop buang air besar sembarangan antara lain sebagai berikut:

1. Aspek social yang mempengaruhi masyarakat di Desa Tambak Baru, Kecamatan Martapura Kabupaten Banjar dalam berperilaku buang air sembarangan, antara lain factor pendidikan, ekonomi dan pola pikir masyarakat dalam berperilaku buang air besar. Untuk pencapaian target stop BABs dilakukan kegiatan pemicuan, agar tercapai perubahan perilaku masyarakat dalam perilaku BABs dengan melakukan simulasi perhitungan tinja dan air tinja, karena masyarakat membuang tinja ke sungai.

2. Aspek teknis yang menjadi kendala adalah factor topografi (dekatnya sungai dengan permukiman warga), dan kurangnya ketersediaan lahan akibat dari padatnya rumah warga sehingga digunakan sistem pengelolaan limbah terpusat dan IPAL Komunal.

\section{DAFTAR PUSTAKA}

Gideon Kesuma, Ir. M.Eng. Pedoman Pengerjaan Beton. Erlangga.

http://ciptakarya.pu.go.id/spbm-usri/ind ex.php?page $=$ sanitasi/tentang

https://id.wikipedia.org/wiki/Sanitasi

Iskandar, M.T. et all, 2005. Bahan Kuliah Struktur Beton Bertulang I. ULM.

Metoda Pembuatan Dan Perawatan Benda Uji Beton Di Laboratorium, SK SNI-M-621990-03.

Perencanaan Pengolahan Sistem Setempat (On-Site System).2015

Rivani, Ir Fachrir,1995. Petunjuk Praktikum Beton, Laboratorium Struktur dan Bahan, Fakultas Teknik ULM. ULM.

Subakti,Aman,1994. Teknologi Beton Dalam Praktek. ITS.

Subakti,Aman,1995. Teknologi Beton. ITS.

Tata Cara Pembuatan Rencana Campuran Beton Normal, SK SNI T-15-1990-03

Tata Cara Pengadukan dan Pengecoran Beton, SK SNIT-281991-03

Tjokrodimuljo, Kardiyono,1996. Teknologi Beton. UGM.

Tri Mulyono, Ir., M.T, 2003. Teknologi Beton. 